\title{
Improving Birth Preparedness and Complication Readiness Through an Integrated Microfinance and Health Literacy Program:Evidence From Rural India
}

\author{
Danish Ahmad ( $\square$ drdanish.research@gmail.com ) \\ University of Canberra Faculty of Health https://orcid.org/0000-0001-7891-3756 \\ Itismita Mohanty \\ University of Canberra Faculty of Health \\ Theo Niyonsenga \\ University of Canberra Faculty of Health
}

\section{Research article}

Keywords: Maternal Health, Community health program, Microfinance program, Health literacy, Self-Help Group, Women Empowerment, Scalable health models, Birth Preperadness and Complication Readiness, Maternal Complications, Program Evaluation

Posted Date: October 15th, 2020

DOI: https://doi.org/10.21203/rs.3.rs-79341/v1

License: (ㄷ) This work is licensed under a Creative Commons Attribution 4.0 International License. Read Full License 


\section{Abstract}

Background:Despite maternal mortality rate almost halving over the past two decades, approximately 295,000 deaths occurred annually in 2017 globally. They occur in high burden regions where most preventable deaths are precipitated by delays in maternal care provision. Recently, a novel rapidly scalable community-based program combining maternal health literacy delivery through microfinance-based womenonly self-help groups (SHG) was implemented in rural India. We evaluated the impact of the IMFHL program on BPCR practice by women in one of India's poorest states-Uttar Pradesh, adjusting for community, household and individual variables. We also investigated if there is a diffusion of knowledge of BPCR from SHG members receiving the health literacy intervention to non-members in program villages.

Method: Using secondary survey data from the IMFHL project, we analysed data from 17,244 women across SHG and non-member households in Uttar Pradesh. We performed multivariable logistic regressions to estimate adjusted IMFHL program's effects on maternal BPCR practice.

Results: Membership in SHG alone is positively associated with BPCR practice with 17 percent higher odds compared to women in villages without the programs. Furthermore, the odds of practising complete BPCR increases by almost fifty percent when a maternal health literacy component is added to the SHGs. A diffusion effect was found for BPCR practice from SHG members to non-members only when an added health literacy component was integrated into the SHG model. The main effect of the IMFHL program on BPCR practice remained stable in the presence of confounders suggesting that the delivery of health messages is undiluted by other non-programmatic factors at the individual, household and community level. Among confounders, only the poorest households as captured by the wealth quintile were significantly negatively associated with BPCR practice.

Conclusion: The public health literature promotes the adoption of BPCR practices to improve maternal health outcomes. This study shows that SHGs exert both a dissemination effect of planned health behaviour within members, as well as facilitate a diffusion effect of the natural transfer of BPCR from members to non-members when SHGs are enriched with a health literacy component

\section{Background}

Improving maternal health is a global priority in the attainment of the Sustainable Development Health Goals (SDG). Health system reforms and improvements in overall socio-economic conditions in low resource countries has led to an almost fifty per cent reduction in maternal deaths by the Millennium Development Goal's end (MDG) in 2015 compared to 1990s level (1-3). However, the rate of decline was inadequate to meet the global MDG target of 75 per cent reduction in maternal mortality rate (MMR), defined as the number of maternal deaths during a given time period per 100,000 live births during the same time period $(3$, 4). Consequently, more than 295,000 maternal deaths occurred in 2017 mostly due to preventable causes in the maternity period, namely due to hypertensive disorders of pregnancy (pregnancy-induced hypertension-PIH/Eclampsia), severe bleeding, obstructed labour and sepsis (4-6). Despite established treatment options for these causes, the high number of unnecessary deaths stemming from these reflect the residual gap from the MDGs. The current SDG era has an even stringent target of reducing MMR to 70 per 100,000 live births by 2030 for all countries (5). Achieving the SDG's maternal health goal requires concerted action in select high poverty and low resource countries in Sub Saharan Africa and South Asia, where almost 99 per cent of global preventable maternal deaths occurred $(1,7,8)$. After Nigeria, India accounts for the world's second-highest maternal deaths with almost 45,000 maternal deaths annually $(9,10)$. Although India has invested substantially in improving health service delivery for its predominantly rural population, high maternal deaths remains a challenge $(6,8)$. Attaining the SDG goal requires specific improvements in high burden regions like India to accelerate maternal mortality decline beyond what was observed in the MDG era, and to adopt novel strategies that bridge health system inadequacies with civil society actions $(11,12)$.

The World Health Organisation (WHO) recommends skilled birth attendance and access to timely emergency obstetric care during maternal complications as crucial interventions to improve maternal and neonatal survival (13). Improving birth preparedness and complication readiness (BPCR) is a crucial strategy to reduce maternal mortality through increasing awareness and preparedness around emergency obstetrics care in low resource settings (13). WHO recommends BPCR as a process of planning by women, households and communities to adopt key guided steps that help families navigate complex decision-making during maternal complications about when to act and where to seek care promptly. According to the WHO, BPCR broadly comprises of the following preventative steps: decide on the place of delivery (home or health facility); identify the facility that could provide emergency care; identify people to accompany the woman to the hospital for delivery; identify people to take care of children at home; save/arrange money for delivery expenses or in case of emergency; make advance arrangement of transportation to go to the facility; identify institution where to rush in case of emergency (13).

Pregnant women and their households are expected to receive BPCR advice as part of the antenatal care services by the health worker or through home visits (13). While the evidence of BPCR effects on maternal mortality reduction is mixed, a 2017 systematic review showed that the adoption of BPCR as part of an intervention package has the potential to improve care-seeking and encourage timely use of health facility

Page $2 / 25$ 
in maternal; and neonatal complications (14). A study from an urban slum in India showed that skilled attendance at birth was almost 30 per cent higher among well prepared compared to less prepared mothers (15). Another study from Uganda showed that past experience of maternal complication and awareness of maternal danger signs are predictors for higher BPCR knowledge (16). Moreover, despite demonstrated benefits of BPCR, studies showed that BPCR is challenging to achieve in low resource settings where health system services are lacking, and households have low education and high poverty levels $(2,12,16-19)$. Studies from other high maternal burden countries in Africa showed that women's BPCR knowledge levels remain low due to health system factors related to poor quality of health education, absence of functional referral system and failure of the health system to implement an adequate policy on BPCR (16, 20).

While India has prioritised institutional delivery through a conditional cash transfer scheme, substantial gaps persist in early identification and care of maternal complications, especially in the antenatal and post-natal period for rural populations (10, 21, 22). Inadequate referral and limited Emergency Obstetric Services (EMOC) place women at higher risk of adverse maternal outcomes in rural areas (12, 22, 23). Heath system inadequacies are compounded by community-related delays in seeking care and reaching health facilities due to financial barriers and lack of birth and complication readiness (22, 24-28). Furthermore, studies showed that women from poor households in rural areas, belonging to certain socio-demographic segments, have a higher risk of maternal deaths compared to wealthier women in urban areas. (2931). In most instances in rural India, decision-making among households during maternal emergencies is influenced by past experiences with the health system and a tendency to follow traditional cultural beliefs $(29,31,32)$. Previously delays in care-seeking have been explained using the widely validated three-delays framework as an approach to develop interventions to improve care-seeking steps (19, 24, 31, 33-35). The framework identifies the recognition of danger signs in the household as the first type of delay, delays in reaching an appropriate facility as the second delay and lastly, delays in receiving adequate care in the health facility (35). While some view household factors as mainly accounting for the first and second delays, and attribute the third delay exclusively to the health system, in an optimal setting, adequate provision of maternal health services would ensure that none of the delays occurs $(19,35)$.

Most avoidable maternal deaths occur in disempowered segments of society, among women who face multiple deprivations related to severe poverty, low education and social marginalisation $(29,31,36-38)$. Verbal autopsy studies in India with family members of deceased women in rural and tribal regions showed that in many settings, women lack adequate information about pregnancy-related danger signs and are inadequately prepared during pregnancy-related complications $(25,29,39)$. In the absence of complications readiness and adequate referral services, families are forced to adopt a harmful wait and watch approach to gauge the severity of underlying maternal distress, often with adverse outcomes $(25,29,39)$. Preparing for birth and complications has, therefore, emerged as a crucial intervention for rural communities to reduce subsequent delays in maternal care-seeking $(24,40)$.

Maternal death reviews showed that select high poverty and low development states in the north of India contribute the majority of maternal deaths $(8,10,30)$. Notably, the state of Uttar Pradesh(UP) which has a population of 200 million and high concentration of rural population(79 per cent), and poverty(31 per cent live below the poverty line), has the highest number of maternal deaths in the country ( 8,10 , 32). MMR in Uttar Pradesh stands at 201 per 100,000 live births compared to the national MMR of 170 per 100,000 live births (10, 42 ).

UP also accounts for a quarter of the neonatal mortality burden of India and shares similar socio-economic, demographic and health system characteristics with other high mortality regions in India and South Asian countries (10). In 2016, UP reported 43 per cent home deliveries, among which only 26 per cent were attended by skilled birth personnel $(43,44)$. Also, among the 33 per cent of pregnant women in rural UP who reported receiving the minimum three antenatal care(ANC) visits (now revised to four), only eight per cent used the recommended 100 tablets of Iron Folic Acid (IFA) suggesting gaps in ANC service delivery (22). Studies from India and rural UP showed that, despite higher institutional deliveries, deficiencies in ANC limits transmission of key maternal health information such as BPCR to pregnant women (22, 43). In a rural setting where antenatal and referral services are inadequate to ensure monitoring of pregnancies irrespective of risk, households' adoption of BPCR, therefore, assumes greater importance $(22,43)$.

Limitations in health systems in low resource settings have given rise to alternative approaches incorporating community efforts to mobilise, educate and empower women to improve maternal health outcomes. While many community mobilisation programs showed success as pilot programs under controlled environments, scaling of these programs to a larger population(s) is challenging. Mainly, due to dilution effects of resources when going from small-scale pilot in a controlled environment to a population level program with real-life conditions (44). Moreover, when community health programs are implemented, access to information and resources is often limited to direct program beneficiaries, potentially excluding specific population subsections or harder to reach groups $(45,46)$. Studies have found that the spread of health information beyond the program participants in a community is influenced by the number and quality of social networks that enhance interpersonal contact to improve health message uptake(47). The role of social networks and community groups is especially pertinent in rural Uttar Pradesh where studies show that up to 70 per cent of women can have no access to traditional sources of media such as radio, television and newspaper(48). These disadvantages in receiving information are compounded by low levels of education that can affect the processing of health information as well as changing health behaviour based on health information $(47,49)$. In such settings, social networks 
that are accepted within the community can facilitate access to health information and reduce disparities among different population groups $(50,51)$. Evidence also shows that health programs led by the community promote the sharing of new knowledge that can expand the reach of community interventions $(50,52,53)$. However, limited research has been conducted in low resource settings to examine whether health information provided through community program facilitates health promotion beyond the primary beneficiaries of the program.

Recently, a promising community-based intervention that builds on the concept of empowering poor rural pregnant women by providing them with health literacy and finance-based assistance through women-only microfinance groups was implemented in rural Uttar Pradesh. The microfinance-based program builds on other community-based programs that showed an improvement in routine indicators of maternal health (54-57). This study evaluated the integrated microfinance and health literacy (IMFHL) program that took advantage of the microfinance platform to provide pregnant and recently delivered women with health messages. Information was provided to identify dangers signs related to pregnancy, childbirth and post-delivery complications, and to adopt birth preparedness and complication readiness steps in order to reduce delays associated with seeking care. The IMFHL program hypothesised that women in households receiving financial access and additional health information through the Self Help Groups(SHG) would be able to reduce health care-seeking delays during maternal complications. Microfinance based SHG platform in UP and other low-development regions of India have previously shown that integrated health literacy and SHG interventions can improve routine maternal health practices such as antenatal care utilisation, institutional deliveries and also improve newborn health practises at home such as cord care and timely breastfeeding(58, 59). However, the impact of membership in a SHG based health program on the practice of BPCR among SHG members has not been evaluated. Also, the potential of the program to diffuse health information from members to non-members in villages where SHGs are established is untested. Diffusion of health messages as defined as the unplanned natural spread of health information and practices in a community is differentiated with the dissemination or planned spread of health information under programs $(60,61)$. This study evaluated both the impact of membership on the dissemination of BPCR practice among members, as well as the diffusion of health practice from SHG -members to non-members within program villages.

This research builds on limited evidence on the effectiveness of membership in integrated microfinance program with health literacy component on birth preparedness and complication readiness practice among women in rural areas $(58,59,62-64)$. The objective of the study is to generate evidence for community health program managers and policymakers on the role of the program as a potentially scalable model for improving maternal health outcomes in India. The study also examines the diffusion effect generated by the program that permits diffusion of BPCR practices and knowledge from members to non-members in rural India.

\section{Method}

\section{Study Aim and Design}

This study evaluated the impact of membership in an integrated microfinance and health literacy (IMFHL) program on the practice of birth preparedness and complication readiness (BPCR) by women during their last pregnancy in rural Uttar Pradesh. The study also, evaluated whether the IMFHL program contributed to the adoption of BPCR among women that did not participate in the IMFHL program as SHG members through a process of diffusion of behaviours from member households to neighbouring non-member households in villages where the program was implemented.

The study uses survey data, collected under the IMFHL project in two rounds, capturing the program's pre-intervention characteristics in round I in 2015 followed by round II of data collection two years into the program in 2017 (58). Under the IMFHL project, a quasi-experimental survey design was used to collect cross-sectional survey data in each round to evaluate the program's impact on mothers' knowledge and health behaviours in low-income households in villages across UP (58)

\section{IMFHL Program Context}

The IMFHL program integrated a maternal and neonatal health literacy component within a microfinance based SHG platform to provide pregnant and recently delivered women with health messages in rural UP. The program was implemented over five years (2012-2017) through a consortium comprising a technical lead, an implementing partner, a research partner and an evaluation partner(58). A detailed description on IMFHL program context, selection of intervention, comparison and control blocks, is available elsewhere (58).

The design of the health literacy intervention was informed by the three delays framework and from successes of the previous nonmicrofinance based participatory community health programs such as the Shivgarh trial in UP, and the Makwanpur trial in Nepal (35,52,55). Health messages were directly provided to women by the IMFHL program using various inter-personal communication strategies, such as an invitation to SHG meetings for health discussion; postal letters to pregnant and new mothers with key health messages timed to delivery and neonate care; reinforced messages through house visits; and exposure to community health video shows developed by the program (58). 
Woman's SHG membership was determined when the woman was a SHG member herself or belonged to a household where someone else, usually a mother in law or sister in law, was a SHG member (58). In the latter case, perfect communication was assumed between the family members. These women (SHG members) represented the first tier of beneficiaries who directly received health information from the SHG, encouraging them to adopt desired health behaviours to promote maternal and neonatal health. The IMFHL project investigators also expected health information to reach non-member women in the same village where SHGs were established and health literacy provided. As members and non-members lived in the same village/environment, the IMFHL project investigators postulated that women receiving health information as SHG members would communicate new knowledge to neighbouring non-member households mainly through informal communication networks that would gradually lead to the adoption of desired behaviours. Previous social network analysis studies conducted on the IMFHL program showed that SHG membership increased recently delivered mother's health advice networks and linkages with community health workers(65). The extent of these social networks in the transfer of health information and practices to non-members is also evaluated in this paper. This diffusion effect of knowledge from members (tier I) to neighbouring non-members (tier II) is depicted in figure 1 below.

\section{Study Setting and Participants}

\section{Sampling Procedure}

The survey sampling design followed Uttar Pradesh's administrative hierarchy and collected data from households in gram panchayats (GP) or villages from 70 blocks in 20 districts, aiming for a representative sample from the program's coverage area (66). Moreover, while the same gram panchayats, blocks and districts, were visited in both survey rounds; different households were sampled and interviewed in each round. A GP is the smallest administrative region in blocks where SHGs were established and from where household survey data was collected. The survey design used a three-stage sampling approach to select survey blocks, GPs or villages and finally, household as depicted in figure 2 . A detailed description of the selection strategy is available elsewhere (58).

\section{Sample Size}

Different outcome measures were used by the IMFHL project investigators to calculate sample size based on the net increase in health behaviours due to program exposure with an expected response rate of 90 per cent (58). The sample size was estimated considering a net increase of seven percentage point in key reproductive maternal, neonatal and child health indicators (RMNCHN), for example, institutional delivery, the number of antenatal care visits and others, after program implementation with 85 per cent power to detect the change, with the usual 5 per cent level of significance and a design effect of 2 (58). Moreover, in order to detect the diffusion from SHG households to nonmember households in program villages, the project investigators also separately determined the sample size based on an estimated five per cent net change in RMNCHN indicators over the two rounds with 80 per cent power, 95 per cent confidence interval, and a design effect of 1.5 (58).

The sample used in this study comprised a total of 17,244 eligible women, of whom 59 per cent or 10,097 women did not belong to SHGs, and 41 per cent or 7,147 women were SHG members. The data was collected at the individual, household and community levels using separate structured questionnaires. The survey collected data from currently married women aged 15 to 49 years who had delivered an infant in the 12 months preceding the survey, and from the household head and village representatives. The interviews were conducted by data collectors trained by evaluation partner who administered interviews in the local language, Hindi, after obtaining verbal informed consent from respondents using computer-assisted personal interview (CAPI) package designed the Census and Survey Processing System (CSPro), a public domain software used for census and survey data (58). As this study sought to capture individual, household and community level influences on BPCR practice among members and non-member women, we customised our study dataset by combining individual-level, household and village levels sub-datasets across rounds to capture the different levels of influence on birth preparedness and complication readiness.

\section{Statistical Analysis}

Multivariable logistic regression modelling was used to evaluate the intervention program's impact on the level of birth preparedness and complication readiness practice among women in rural Uttar Pradesh. The main explanatory variable, IMFHL intervention, was categorised according to four levels of household's exposure to IMFHL program. Covariates or other confounding variables were chosen based on the broader maternal and child health literature to represent individual, household, and community-level characteristics. Four separate regression models were fitted to the data with the first model (Model I) establishing the program's main effect without any confounding variables but including the survey round variable. The second model (Model II) included an interaction term (IMFHL intervention by survey round) to draw out the change over time, in the effect of IMFHL program exposure. Confounders related to individual health were included in the Model III, while the full model, Model IV included socio-demographic, economic and area-level variables. 


\section{Outcome, explanatory and confounding variables}

i. Outcome variable: The outcome variable, birth preparedness and complication readiness (BPCR) practice captured eligible women's selfreported BPCR steps that were taken during the last pregnancy. A binary variable was constructed with ' $O$ ' representing partial or no BPCR preparation, and ' 1 ' representing complete BPCR defined as when households practised all birth preparedness and complication readiness steps during last pregnancy as outlined by the WHO. In the IMFHL program, women belonging to SHGs in the intervention villages (SHG and health literacy) were provided with the guidance of key steps required for complete BPCR in the pregnancy. The survey collected data from all women on self-recalled steps of BPCR undertaken in the last pregnancy. In both survey rounds, eligible women, independent of the place of delivery, were asked to recall multiple responses to the question "What advance preparation did you/your family members make to manage in case of any pregnancy/delivery complications?". The interview responses were marked against eight key steps required to fulfil birth and complication readiness such as: 'Decided on the place of delivery-home or health facility' 'Knew the facility that could provide emergency care'; 'Identified institution where to rush in case of emergency'; 'Identified people to accompany the woman', 'Identified people to take care of children at home', 'Saved/arranged money for delivery expense or in case of emergency', 'Advance arrangement of transportation to go to the facility' and 'others -cloth, soap'. Although individual steps corresponded to either birth preparedness or only complication readiness were practised, complete BPCR was determined when a household followed all steps, in accordance with current WHO guidelines on BPCR. According to WHO, complete BPCR was defined when the woman and household fulfilled all the steps that provided families a greater opportunity for readiness in the event of a maternal emergency.

ii. Main explanatory variable. The exposure variable, the IMFHL intervention, comprised of four levels based on households' exposure to the IMFHL program. An ordinal variable was created allowing to evaluate the program's main effect on the practice of BPCR, that is, the magnitude of change in BPCR practice across levels of the IMFHL program exposure: intervention (SHG plus health), comparison (SHG only) and pure control (no SHG, no health) households. The coding of the IMFHL explanatory variable with description is shown below:

- Group 0: Comprised of households that were not SHG members (non-members) and were in villages without any program intervention (pure control households).

- Group 1: Comprised of households that were not SHG members (non-members) but were in program villages where either the SHG program alone or SHG program plus Health intervention was implemented (diffusion-control households).

- Group 2: Comprised of households that were SHG members in program villages where only SHG program was implemented (comparison households).

- Group 3: Comprised of households that were also SHG members but were in villages where both the SHG program and additional health intervention was provided. Only these households received health literacy intervention through the SHG (intervention households).

iii. Additionally, a survey round variable was created to assess the effect of intervention program over time (change in women's BPCR in round II in 2017 compared to round I in 2015 when the program was yet to be implemented).

iv. Confounding variables: A comprehensive set of confounding variables capturing individual, household and community-level characteristics were identified from previous maternal and child health literature and included in models III and IV. Confounding variables in model III represented eligible woman's maternal health status and broader maternal health service utilisation indicators such as parity, the experience of pregnancy-related complication in a previous pregnancy, number of previous pregnancy loss, knowledge of minimum ANC visits required, place of last delivery. Additional socio, demographic and area-level characteristics were included in the final Model IV, namely: type of family (nuclear versus joint or extended), religion, household's social caste, education level of the eligible woman and her husband. Model IV also included a household wealth quintile, constructed for this analysis using Polychoric Principal Component Analysis (PCA), combining all household assets and amenities to evaluate BPCR association across five wealth gradients extending from marginally poor (reference category) to the poorest households.

\section{Summary Results}

Table 1 provides results of individual steps undertaken in the study sample towards birth preparedness and complication readiness (BPCR) practice in last pregnancy among women aged 15-49 in rural Uttar Pradesh $(n=17,244)$. Table 1 and Figure 3 reveals, only 24 per cent of all women in this analysis had not practised any steps for birth or complication readiness; however, 76 per cent women had some level of BPCR readiness with 49 per cent had undertaken full BPCR in last pregnancy. Also, 6 per cent of women had taken steps fulfilling only birth preparedness while only 21 per cent of all women had undertaken the three steps required for complication readiness.

Table 2 presents the summary results for eligible women categorised across (SHG) member and non-member households across all variables used in this paper. The study sample comprised of more women from non-member households (59 per cent) but with an equal allocation of households within various levels of IMFHL program exposure levels. Surveyed women had a mean parity of $2 \cdot 4$ (median 2, range 0-9) which 
similar as in rural UP, but, it is higher than the current Indian fertility rate (median $=2 \cdot 2$, range: $2 \cdot 1-4)(44)$. Moreover, close to 48 per cent of all women reported experiencing a pregnancy complication in their last pregnancy, while only a quarter ( 25 per cent) had suffered a spontaneous or induced abortion. Furthermore, women on average had four contacts with frontline workers in the previous pregnancy, with 26 per cent of women receiving four ANC with all tests during the last pregnancy and only nine per cent women receiving the vital three post-natal visits in the first week after delivery. Contrary to this, 83 per cent of all women reported having an institutional delivery in a public or private facility. However, women reported a shorter duration of stay in a health facility after delivery with almost 67 per cent discharged earlier than the Indian government mandated 48 hours stay for normal (non-emergency or caesarean) deliveries(22). In terms of area-level characteristics, villages were at an average distance of 5.4 kilometres $(\mathrm{km})$ to the closest primary health centre (PHC). Lastly, about 46 per cent of households had access to the Below Poverty Limit Card (BPL)

By design, the IMFHL program was implemented in poor rural areas of Uttar Pradesh which the statistics show with only 16 per cent of women working to earn cash or kind. Moreover, within households, the majority (92 per cent) of households belonged to the Hindu religion, the predominant religion in UP and India, while 45 per cent identified themselves as belonging to Scheduled caste and tribes. The sampled women had a mean age of 25 years, with 66 per cent of all women have received some form of education, while husband's education level showed 83 per cent had received some form of schooling. Finally, according to the levels of BPCR, the outcome variable, 52 per cent of all SHG households had a complete BPCR plan in place in the last pregnancy, while 46 per cent of women in non-member households had all BPCR steps in place in the last pregnancy.

\section{Results}

The results from multiple logistic regression models are presented in Table 3 with models I and II providing the main effects of program exposure levels and survey round on BPCR practice. Models III and IV in Table 4 shows the results of IMFHL program exposure survey round on BPCR adjusting for socio-demographic, economic and area-level confounders. The individual model coefficients were estimated using the maximum likelihood estimation method. The Odds Ratio (OR) values are reported, as measures of the strength of association, along with their associated 95 per cent confidence intervals $(95 \% \mathrm{Cl})$ and $\mathrm{p}$ values.

\section{Model I: IMFHL program's effects on birth preparedness and complication readiness}

Women belonging to SHG alone, and those receiving health intervention from SHG, both reported higher odds of practising birth and complication readiness in last pregnancy compared to the non-member in control(non-program)villages (Table 3). While, women in SHG households were 17 per cent or $1 \cdot 17$ times more likely to have practised BPCR in their last pregnancy $(0 R=1 \cdot 17,95 \%$ Cl: $1 \cdot 07-1 \cdot 29, p<0 \cdot 01)$ compared to non-members in control villages. SHG members who received additional health literacy were 48 per cent or 1.48 times more likely to practice BPCR (OR=1·48, 95\% Cl: 1·35-1·63, p<0.01) compared to non-members in control villages. However, results also showed that non-member women living in villages where either SHG or SHG plus health intervention was implemented, were 11 per cent less likely to practise BPCR compared to non-member women in control villages, that is, where no SHG nor health was implemented (OR=0.89, 95\% $\mathrm{Cl} \cdot 0 \cdot 82-$ $0.97, p<0.01)$. The models also evaluated the effect of program implementation overtime on BPCR using the variable, survey round. The results showed that women in households interviewed in round II were almost 63 per cent or 0.37 times less likely to have practised BPCR compared to households interviewed in the round I given all the levels of program exposure $(0 \mathrm{R}=0 \cdot 37,95 \% \mathrm{Cl}: 0 \cdot 35-0 \cdot 39, \mathrm{p}<0 \cdot 01)$.

\section{Model II: Interaction effect of IMFHL program and Survey Round}

The program exposure is expected to mature in implementation between round I in 2015 when the maternal health literacy component was started, and in 2017, two years into the intervention when round II was conducted. The program effect on BPCR, therefore, is expected to vary over round I and II. Model II, therefore included an interaction term of program exposure with survey round to capture the project's influence on BPCR over time.

Model II showed that the inclusion of the interaction term changed the direction and magnitude of the impact of the program exposure (for women in SHG plus health households) on the practice of BPCR compared to the same household type in model I. The results showed that these women now reported a statistically insignificant four per cent lower odds of practising BPCR compared with non-member women in control villages $(\mathrm{OR}=0.96,95 \% \mathrm{Cl}: 0 \cdot 84-1 \cdot 11, \mathrm{p}>0 \cdot 10)$. The shift in direction and magnitude observed for women in SHG plus health households between models I and II are suggestive of an underlying significant interaction effect of program exposure and survey round.

The results from the two-way interaction in Model II showed that women in SHGs that received health literacy were $2 \cdot 21$ times more likely to practice birth preparedness and complication readiness in the second round compared to same household type in the first round (OR=2.21, $95 \% \mathrm{Cl}: 1 \cdot 82-2 \cdot 68, \mathrm{p}<0 \cdot 01)$. This means that women in the intervention group were roughly $2 \cdot 122(=0 \cdot 96 * 2 \cdot 21)(95 \% \mathrm{Cl} \cdot 1 \cdot 52-2 \cdot 97)$ times more likely to practice BPCR in survey round II compared to women in control villages. Similarly, the results showed that non-members in program 
villages reported 1.73 times higher odds of BPCR practice in round II compared to the same household type in the first round (OR=1.73,95\% Cl: $1 \cdot 46-2 \cdot 05, p<0 \cdot 01)$. The difference in odds ratio suggests that the health literacy intervention impacted BPCR practice after program implementation as reflected in round II. These results indicate that a diffusion effect occurred from SHG women receiving health literacy to non-member women in the same villages, with women in this group being roughly $1 \cdot 194(=0 \cdot 69 * 1 \cdot 73)(95 \% \mathrm{Cl}: 0 \cdot 89-1 \cdot 57)$ times more likely to practice BPCR. However, the results of the two-way interaction effect revealed that women in SHG only households in round II did not report a significant change in BPCR practice in last pregnancy compared to the same group of women in round I as shown in Table 3. Therefore, the results show that the source of the diffusion of BPCR practices in non-members is due to the health literacy intervention in SHG villages, and not due to the SHG only network.

\section{Model III and IV: Effects of IMFHL program adjusted for confounders}

The effect of program exposure was further evaluated in model III and IV in Table 4 when confounders were added. Overall, the effect of program exposure on BPCR observed previously in model II remained unaffected when adjusted for confounders in model III and IV, suggesting that the outcome is mainly influenced by program variables rather than confounders. However, the results of key confounders in model III and IV holding the main program exposure variable and others constant are reported as follows.

\section{Effects of individual health and health system variables}

Among variables reflecting the continuum of maternal care, women with the correct knowledge of ANC visits were more likely to practise BPCR compared to those with incorrect knowledge $(\mathrm{OR}=1 \cdot 06,95 \% \mathrm{Cl}: 0 \cdot 99-1 \cdot 13, \mathrm{p}<0 \cdot 10)$. Similarly, women who were discharged earlier from the health facility after delivery reported higher odds of practising all steps of BPCR in last pregnancy $(O R=1 \cdot 15,95 \% \mathrm{Cl}: 1 \cdot 00-1 \cdot 33, p<0 \cdot 05)$. Contrastingly, women who reported receiving four ANC with key tests done in the last ANC visit reported lower odds of BPCR practice compared to women who received less than four visits and with incomplete tests $(\mathrm{OR}=0 \cdot 90,95 \% \mathrm{Cl}: 0 \cdot 82-0 \cdot 99, \mathrm{p}<0 \cdot 05)$. Other variables reflecting individual health status such as parity, pregnancy complication experience and health system variables such as contact with front line workers were found be statistically insignificantly associated with BPCR holding other variables constant up to a p-value of 10 per cent. Separate multivariate analyses conducted in this study (results not shown), found that more health variables became statistically associated with BPCR, albeit negatively when round and the interaction term, IMFHL by round, were removed from the full regression models. For example, in the absence of round and IMFHL by round, women with any history of previous pregnancy loss, and those who experienced pregnancy complication were now almost 8 per cent less likely to practice BPCR compared to those with no previous pregnancy loss history $(\mathrm{OR}=0.92,95 \% \mathrm{Cl}: 0 \cdot 86-0.99, \mathrm{p}<0.05)$ and experience of complication $(\mathrm{OR}=0.94,95 \% \mathrm{Cl}: 0 \cdot 88-1 \cdot 00, \mathrm{p}<0 \cdot 10)$. These results suggest that the round variable and the interaction term of IMFHL by round are exerting a subduing effect on the association of health status variables with the outcome in this analysis. As health behaviours, such as BPCR, may also be influenced by wider social, demographic and economic factors, in model IV tested the effect of these confounders that are described next.

\section{Effect of socio-demographic, economic and area-level variables}

Model IV results revealed that the impact of program exposure on birth and complication readiness was unaffected by the adjustment for socio-demographic variables. A wealth quintile variable was constructed based on household asset ownership for this study and included in the regression to describe the economic status of the household beyond the use of the BPL card variable. Results from the wealth quintile showed that the likelihood of BPCR practice reduced as the level of household poverty increased from marginally poor to the poorest households, with the poorest households in the fifth quintile, 23 per cent or 0.87 times less likely to practice birth preparedness and complication readiness compared to women in marginally poor households, or first quintile. Maternal education which has previously been found in the literature to be strongly correlated with routine maternal health behaviours, in contrast, was negatively associated with BPCR practice in this analysis. Mothers who had completed primary education, and more are seven per cent less likely to practice BPCR compared to mothers without any schooling ( $\mathrm{OR}=0 \cdot 93,95 \% \mathrm{Cl}: 0 \cdot 87-0 \cdot 99, \mathrm{p}<0 \cdot 05)$. The increasing level of husband's education was, however, found to be positively associated with BPCR practice, but the results were not statistically significant $(\mathrm{OR}=1 \cdot 02,95 \% \mathrm{Cl} \cdot 0 \cdot 95-1 \cdot 11, \mathrm{p}>0 \cdot 10)$.

\section{Discussion}

This study makes a significant contribution to the literature in investigating the main effect of the IMFHL program membership on birth preparedness and complication readiness (BPCR) practice among women who have recently given birth in rural UP. The study provides evidence of the benefits of SHG membership alone and when integrated with health literacy on improving BPCR practice. This evidence suggests that care-seeking is potentially improved during maternal complications among SHG members, and supports the claim that microfinance based women's groups are an effective strategy to provide health literacy to marginalised rural populations for enabling behaviour change. No previous study in the Indian context or elsewhere has examined BPCR in the context of a SHG program alone or in an integrated SHG and health literacy program. This is the first study to our knowledge that demonstrates the presence of a diffusion effect of 
health behaviour, BPCR practice, from SHG members receiving health literacy to non-members in program villages. Overall, the results reveal that SHGs promote the adoption of BPCR practice among members and the odds of BPCR adoption almost doubles when a health literacy component is integrated into the model. However, the diffusion effect of BPCR practice is only observed when SHGs have an integrated health literacy component. Therefore, these findings suggest that self-help group requires the addition of a maternal health literacy component to achieve a higher coverage of a behavioural health intervention among members and non-members in villages. The underlying mechanism of diffusion requires additional research to explain pathways; however, insights from previous studies suggest that either SHG members may themselves be promoting practices as 'model adopters' of new behaviour through interpersonal contact, or that SHGs serve as a better platform for facilitating linkages between non-members and community health workers when added with health literacy intervention(66, 68 , 69). It is therefore feasible that when SHG members receive health literacy, they may be acting as change-agents to encourage other nonmembers to adopt desired health behaviours.

Prior, studies in Uttar Pradesh have shown no association of SHG membership alone with routine maternal health practices in pregnancy such as antenatal care, institutional delivery. However, our study, in contrast, found an improvement in BPCR practice for women in SHGs (63, $68,69)$. Our findings are supported by other studies from Uttar Pradesh and Bihar, also a state with low development indicators, that showed an increase in routine indicators of maternal health system utilisation( such as four ANC, institutional delivery etcetera) and home-based neonatal health care practices by 5-11 percentage points when health literacy intervention was provided through SHGs compared to membership in SHG alone $(58,59)$. Our study showed that the peer effect of membership in SHG alone is associated with a 17 per cent higher likelihood of practising BPCR, which increases to 48 per cent when a health literacy component is delivered through it. The higher likelihood of BPCR practise among women in SHG's alone is explainable as a direct consequence of SHG membership which grants women with access to funds needed. This access fulfils one of the key steps for BPCR with regards to saving funds for a maternal emergency. Despite higher institutional deliveries in rural India which are financially incentivised for women and health workers, studies in India have shown that incentivisation meets only 25 per cent of total maternal expense in rural areas (70). Studies from rural India showed that marginalised families are more likely to incur higher out of pocket expenditure (OOPE) ranging from USD 11-16 (INR 700-970) depending on whether the delivery is normal or complicated. Such expenses are considerable for populations analysed in this paper where the average monthly household income is USD 25. High maternal health expenses are counted as a strong factor for pushing vulnerable families at the risk of poverty into debt traps which reinforce cycles of debt borrowing and illness. Therefore, in such settings, the provision of health literacy and financial access is expected to improve households' care-seeking preferences. Our results are further supported by previous studies that have shown that SHGs provide mutual support among members $(59,67)$. Therefore, health literacy delivered through the peer network of SHG is likely to change health practices among marginalised women. In the IMFHL project, pregnant women in intervention villages received personalised health messages through house visits by SHG health volunteers, and through invitations to SHG meetings where discussions were set in community settings that allowed addressing community norms about health behaviours. Previously, a systematic review reported that combining home visits and community group meetings is an effective strategy to improve maternal and neonatal health outcomes(71). Yet scarce evidence exists that describe health outcomes when community programs combine microfinance provision and maternal health literacy, such as this program.

Our study also showed that adjusting for other socio-economic confounders BPCR was only associated with the poorest households in the fifth wealth quintile, with these households least likely to practice BPCR. Moreover, the study showed that increasing years of education for neither the woman nor her husband were statistically associated with BPCR practice compared to those who had no education. This finding differs from another study in India that showed significant associations between BPCR practices in an urban slum and both maternal literacy and availing antenatal services (15). While the rural demographics of our study differ from the urban slum study environment, women included in the IMFHL program share some commonalities with the urban slum, since they represent a population with higher social marginalisation, higher mortality and low literacy, from areas of Uttar Pradesh where the quality of health services was lacking.

\section{Study Strengths and Limitations}

The key strengths of the study include: the community program strategy that combined microfinance and health literacy components; the use of a large sample size of 17,244 women representing marginalised rural populations; the quasi-experimental study design with pre- and postintervention measurements that is possibly the most efficient approach in a highly populated developing country's context, providing the opportunity to evaluate the incremental change across program exposure levels (impact of SHG only, SHG plus health intervention), and the potential diffusion effect (impact of SHG plus health intervention from members to non-members in areas without any program exposure).

However, our findings need to be considered in the context of some limitations. First, the selection of program blocks under the IMFHL was based on the program's operational criterion, therefore, preventing randomisation. The quasi-experimental survey design, however, adopted a multistage sampling using different criterion to select blocks (SC/ST percentage) and villages (SHG coverage and population size) to limit 
selection bias and allow for comparisons of areas with similar socio-cultural and economic characteristics. Second, the study's crosssectional survey design prevents concluding causality.

A third limitation relates to the survey data used for the study, which was collected from women based on self-recall, which is susceptible to recall bias and social desirability. However, the potential for these errors is minimised as the women were interviewed within 12 months postdelivery and by trained interviewers who conducted the interviews. Finally, while the survey design selected women from SHG member and non-member households from the same villages, in some cases, the women sampled in a given village would be either all members or all nonmembers, which potentially limited the variation in the outcome variable within villages. This study therefore assessed the program impact on outcome across villages instead of within villages.

\section{Policy and program implications}

A programmatic strength of the IMFHL intervention was that it utilised the existing structure of the SHG program to embed the health literacy component, which provided evidence of a scalable model for disseminating health information. The findings reported in this study are relevant for the rural Indian context where the Indian government is establishing a network of women-only SHGs as a national poverty alleviation program. Therefore, allowing the integration of the health intervention into SHG structures as done for the IMFHL program permits improving maternal health outcomes for the state and the country.

Another strength of the study, in terms of policy implications, is the design of the health outcome to reflect the complete practice of BPCR as opposed to limited BPCR steps reflecting partial practice used other studies. Complete BPCR allows inferring wider protection of care-seeking steps for women experiencing maternal complications and living in disadvantaged households.

Lastly, as health care-seeking behaviours are shaped by cultural practices in the community settings, the diffusion effect of health messages from members to non-members can reinforce desired health behaviours. Diffusion also increases program coverage of harder to reach populations. Future research is required to explore the pathways of diffusion effect of knowledge and practice from members to nonmembers in program villages.

\section{Conclusions}

The integrated microfinance and health literacy (IMFHL) program evaluated in this study promoted behaviour changes amongst some of the most marginalised households in India's most populated and a developmentally disadvantaged state, Uttar Pradesh. The study evaluation focussed first on the IMFHL program's main effect on BPCR practice, independent of potential confounders. The evaluation then adjusted for potential confounders and separately assessed the association of multiple confounders on household decision making for BPCR adoption. The results show that SHGs exert both a dissemination effect of planned health behaviour within members, as well as a diffusion effect of the natural transfer of BPCR from members to non-members but only when a health literacy component is added to SHGs. Based on the study findings, the authors would recommend integrating health literacy components into SHG networks and similar community groups to promote household's adoption of complication readiness plans to reduce delays in seeking health care during maternal complications.

The inclusion of health literacy in a microfinance platform presents an example of a novel community-based strategy that has the potential to interrupt the cycle of household poverty and low maternal healthcare-seeking. Lessons from the IMFHL program implementation in India provide the opportunity to adapt SHG models implemented elsewhere by adding health literacy components. Beyond India, microfinance is promoted globally as a poverty alleviation program in low resource settings where the burden of maternal mortality remains high. This can assist other low resource settings in accelerating progress towards the maternal health goal of the Sustainable Development Goals (SDG)

\section{Abbreviations}

\section{SHG}

Self- help groups; IMFHL:Integrated microfinance and health literacy ; MDG:Millennial Development Goals; SDG:Sustainable Development Goals; MMR:maternal mortality ratio; EMOC:Emergency Medical Obstetric Care; UP:Uttar Pradesh; USD:United states dollars; ANC:Antenatal care; IFA:Iron-folic acid; PPH:postpartum haemorrhage; PNC:post-natal care; PHFI:Public Health Foundation of India; PC:Population Council; BU:Boston University; RGMVP:Rajiv Gandhi Mahila Vikas Pariyojan ; BMGF:Bill and Melinda Gates Foundation SC/ST:Scheduled caste /Scheduled tribe; GP:gram panchayats; PP:percentage point:CAPI:computer-assisted personal interview:PCA:Principal Component Analysis; OR:Odds ratios; CAIC:Consistent Akaike Information Criteria; BIC:Bayesian Information Criteria:PHC:Primary Health Centre; KM:Kilometre; EW:Eligible woman; ASHA:Accredited Social Health Worker; ANM:Auxiliary Nurse Midwife; AWW:Anganwadi worker; Cl:Confidence intervals; BPL:Below poverty limit:MNH:Maternal and newborn health:BPCR:Birth Preparedness and Complication readiness

\section{Declarations}




\section{Ethics approval and consent to participate}

Ethics approval was granted by the Human Research Ethics Committee, at the University of Canberra. Previously, an independent ethics committee of the evaluation partner approved the primary data collection under the IMFHL project.

\section{Availability of data and materials}

The datasets used and/or analysed during the current study are available from the corresponding author on reasonable request.

\section{Competing interests}

The author(s) declare(s) that they have no competing interests.

\section{Funding}

The paper is part of the PhD research of the first author (Danish Ahmad) who is supported by the University of Canberra's Higher Degree by Research scholarship for his PhD. Open access funding for the publication is provided by the Bill and Melinda Gates Foundation who also funded the IMFHL program evaluated in the paper. The funders had no role in study design, data collection and analysis, decision to publish, or preparation of the manuscript.

\section{Author Contribution}

DA conceptualised the study, conducted the analysis, interpreted the results and drafted the study.IM guided the study design, the data analysis, the interpretation of the results and discussion. IM provided substantive feedback and reviewed all drafts of the paper. TN guided the study design, the data analysis and interpretation of results and discussion. TN provided substantive feedback and reviewed all drafts of the paper.

\section{Acknowledgment}

We wish to thank Professor Rachel Davey, Health Research Institute, the University of Canberra, for her guidance and reviewing the final draft of this manuscript. The authors would also like to thank the University of Canberra (Australia), the Public Health Foundation of India (India), Population Council (India) for supporting this international research collaboration.

Lastly, the authors thank the Bill and Melinda Gates Foundation for supporting the dissemination of research from their funded health program(s) in India.

\section{Author Information}

Danish Ahmad is a medical doctor and public health professional with interest in health system strengthening, implementation science, and implementation of community-based health programs. Dr Itismita Mohanty is a Senior Research Fellow in Health Economics at the Health Research Institute, Faculty of Health, University of Canberra where she conducts advanced quantitative modelling for health system research and supervises doctoral students in public health. Dr Theo Niyonsenga is Associate Professor of Biostatistics, University of Canberra (UC) Faculty of Health, where he designs and conducts health program evaluation and supervises doctoral students in public health.

\section{References}

1. Berman P, Requejo J, Bhutta ZA, Singh NS, Owen H, Lawn JE. Countries' progress for women's and children's health in the Millennium Development Goal era: the Countdown to 2015 experience. BMC Public Health [Internet]. 2016;16(S2):791. Available from: http://bmcpublichealth.biomedcentral.com/articles/10.1186/s12889-016-3398-x

2. Moucheraud C, Owen H, Singh NS, Ng CK, Requejo J, Lawn JE, et al. Countdown to 2015 country case studies: what have we learned about processes and progress towards MDGs 4 and 5? BMC Public Health [Internet]. 2016 [cited 2017 Oct 19];16(2). https://doi.org/10.1186/s12889-016-3401-6

3. United Nations. The Millennium Development Goals Report. United Nations. 2015;72.

4. Alkema L, Chou D, Hogan D, Zhang S, Moller AB, Gemmill A, et al. Global, regional, and national levels and trends in maternal mortality between 1990 and 2015, with scenario-based projections to 2030: A systematic analysis by the un Maternal Mortality Estimation InterAgency Group. Lancet [Internet]. 2016;387(10017):462-74. Available from: http://dx.doi.org/10.1016/S0140-6736(15)00120-8

5. Department of Economic and Social Affairs, United Nations. The Sustainable Development Goals Report [Internet]. United Nations. New York; 2016. Available from: https://unstats.un.org/sdgs/report/2019/The-Sustainable-Development-Goals-Report-2019.pdf 
6. Trends in maternal mortality 2000 to 2017: estimates by WHO, UNICEF, UNFPA, World Bank Group and the United Nations Population Division. [Internet]. World Health Organization. Geneva; 2019. Available from: https://www.who.int/reproductivehealth/publications/maternal-mortality-2000-2017/en/

7. Ronsmans, C., \& Graham W. Maternal mortality: who , when , where, and why. Lancet [Internet]. 2006;368(9542):1189-200. Available from: https://www.thelancet.com/journals/lancet/article/PIIS014067360669380X/fulltext

8. Gowda SD. Millennium Development Goals - Final Country Report of India. 2017;(September):222. Available from: http://www.mospi.gov.in/sites/default/files/publication_reports/MDG_Final_Country_report_of_India_27nov17.pdf\%0Awww.mospi.gov.in

9. Kassebaum NJ, Barber RM, Bhutta ZA, Dandona L, Gething PW, Hay SI, et al. Global, regional, and national levels of maternal mortality, 1990-2015: a systematic analysis for the Global Burden of Disease Study 2015. Lancet [Internet]. 2016;388(10053):1775-812. Available from: http://linkinghub.elsevier.com/retrieve/pii/S0140673616314702

10. Office of The Registrar General of India. Special Bulletin on Maternal Mortality in India 2015-17 [Internet]. 2019. Available from: http://www.censusindia.gov.in/vital_statistics/SRS_Bulletins/MMR_Bulletin-2015-17.pdf

11. Koblinsky M, Moyer CA, Calvert C, Campbell J, Campbell OMR, Feigl AB, et al. Quality maternity care for every woman, everywhere: a call to action. Lancet [Internet]. 2016;388(10057):2307-20. Available from: http://dx.doi.org/10.1016/S0140-6736(16)31333-2

12. Graham W, Woodd S, Byass P, Filippi V, Gon G, Virgo S, et al. Diversity and divergence: the dynamic burden of poor maternal health. Lancet [Internet]. 2016;388(10056):2164-75. Available from: http://dx.doi.org/10.1016/S0140-6736(16)31533-1

13. World Health Organization. WHO recommendations on health promotion interventions for maternal and newborn health. $2015 ; 3(2): 94$. Available from: https://www.who.int/maternal_child_adolescent/documents/health-promotion-interventions/en/

14. Solnes Miltenburg A, Roggeveen Y, Roosmalen J, Smith H. Factors influencing implementation of interventions to promote birth preparedness and complication readiness. BMC Pregnancy Childbirth. 2017;17(1):1-17.

15. Agarwal S, Sethi V, Srivastava K, Jha PK, Baqui AH. Birth preparedness and complication readiness among slum women in Indore city, India. Journal of Health Population and Nutrition. 2010;28(4):383-91.

16. Mbalinda SN, Nakimuli A, Kakaire O, Osinde MO, Kakande N, Kaye DK. Does knowledge of danger signs of pregnancy predict birth preparedness? A critique of the evidence from women admitted with pregnancy complications. Health Research and Policy Systems. 2014;12(1):1-7.

17. Campbell O, Graham WJ. Maternal Survival 2 Strategies for reducing maternal mortality: getting on with what works. 2006;368:1284-99. Available from: https://pubmed.ncbi.nlm.nih.gov/17027735/

18. Markos, Desalegn Bogale D. Birth preparedness and complication readiness among women of child bearing age group in Goba woreda, Oromia region, Ethiopia. BMC Pregnancy Childbirth [Internet]. 2014;14(1):1-9. Available from: https://bmcpregnancychildbirth.biomedcentral.com/articles/10.1186/1471-2393-14-282

19. Mbachu II, Ezeama C, Osuagwu K, Umeononihu OS, Obiannika C, Ezeama N. A cross sectional study of maternal near miss and mortality at a rural tertiary centre in southern nigeria. BMC Pregnancy Childbirth. 2017;17(1):1-8.

20. Kananura RM, Tetui M, Bua J, Ekirapa-Kiracho E, Mutebi A, Namazzi G, et al. Effect of a participatory multisectoral maternal and newborn intervention on birth preparedness and knowledge of maternal and newborn danger signs among women in Eastern Uganda: A quasiexperiment study. Glob Health Action [Internet]. 2017;10(0). Available from: https://doi.org/10.1080/16549716.2017.1362826

21. Countdown to 2015. Maternal, New Born and Child Survival: India 2015 report. 2015;(000):142-3.

22. National Rural Health Mission. 10th Common review mission [Internet]. Government of India. 2016. Available from: http://nhm.gov.in/images/pdf/monitoring/crm/10th-crm/Report/10th_CRM_Main_Report.pdf

23. Saxena D, Vangani R, Mavalankar D V., Thomsen S. Inequity in maternal health care service utilisation in Gujarat: Analyses of districtlevel health survey data. Glob Health Action. 2013;6(1). doi:10.3402/gha.v6i0.19652

24. Knight HE, Self A, Kennedy SH. Why Are Women Dying When They Reach Hospital on Time? A Systematic Review of the "Third Delay." PLoS One. 2013;8(5). doi: 10.1371/journal.pone.0063846

25. Sri S, Khanna R, Abhiyan JS. Dead Women Talking [Internet]. Dead Women Talking. 2018 [cited 2017 Nov 9]. Available from: http://www.commonhealth.in/Dead Women Talking full report final.pdf

26. Gabrysch S, Campbell OMR. Still too far to walk: Literature review of the determinants of delivery service use. BMC Pregnancy Childbirth [Internet]. 2009;9(1):34. Available from: https://doi.org/10.1186/1471-2393-9-34

27. Chaturvedi S, Randive B, Diwan V, De Costa A. Quality of obstetric referral services in India's JSY cash transfer programme for institutional births: A study from madhya pradesh province. PLoS One. 2014;9(5). https://doi.org/10.1371/journal.pone.0096773

28. Institute for Health Metrics and Evaluation (IHME). GBD PROFILE: INDIA. Global Burden of Disease Study 2010 (GBD 2010 ). 2010;2010(Gbd):1-4. Available from:

Page $12 / 25$ 
http://www.healthdata.org/sites/default/files/files/country_profiles/GBD/ihme_gbd_country_report_india.pdf.

29. United Nations. India and the MDGs Towards a sustainable future for all. 2015.

30. Sri S, Khanna R, Abhiyan JS. Dead Women Talking A civil society report on maternal deaths in India People's Health Movement -India. [cited 2017 Nov 12]; Available from: http://www.commonhealth.in/Dead Women Talking full report final.pdf

31. Aruldas K, Kant A, Mohanan PS. Care-seeking behaviors for maternal and newborn illnesses among self-help group households in Uttar Pradesh, India. J Health Popul Nutr. 2017;36(Suppl 1):49. https://doi.org/10.1186/s41043-017-0121-1

32. Montgomery AL, Ram U, Kumar R, Jha P, Million Death Study Collaborators for TMDS. Maternal mortality in India: causes and healthcare service use based on a nationally representative survey. PLoS One [Internet]. 2014 [cited 2017 Nov 12];9(1):e83331. Available from: doi:10.1371/journal.pone.0083331 1

33. Nambiar D, and Mander $\mathrm{H}$. Health care for urban poor populations Inverse care and the role of the state: the health of the urban poor. Bull World Health Organ [Internet]. 2017;95(2):152-3. Available from: https://doi.org/10.2471/BLT.16.179325

34. MacDonald T, Jackson S, Charles MC, Periel M, Jean-Baptiste MV, Salomon A, et al. The fourth delay and community-driven solutions to reduce maternal mortality in rural Haiti: A community-based action research study. BMC Pregnancy Childbirth. 2018;18(1):1-12. doi:10.1186/s12884-018-1881-3

35. Pacagnella RC, Cecatti JG, Osis MJ, Souza JP. The role of delays in severe maternal morbidity and mortality: Expanding the conceptual framework. Reprod Health Matters [Internet]. 2012;20(39):155-63. Available from: http://dx.doi.org/10.1016/S0968-8080(12)39601-8

36. Mccarthy J, Maine D. A Framework for Analysing the Determinants of Maternal Mortality. Stud Fam Plann [Internet]. 1992;23(1):23.

37. Bhattacharyya S, Srivastava A, Roy R, Avan BI. Factors influencing women's preference for health facility deliveries in Jharkhand state, India: A cross sectional analysis. BMC Pregnancy Childbirth [Internet]. 2016;16(1):1-9. Available from: http://dx.doi.org/10.1186/s12884016-0839-6

38. Chomat AM, Solomons NW, Montenegro G, Crowley C, Bermudez OI. Maternal health and health-seeking behaviors among indigenous Mam mothers from Quetzaltenango, Guatemala. Rev Panam Salud Publica [Internet]. 2014;35(2):113-20. Available from: http://www.ncbi.nlm.nih.gov/pubmed/24781092

39. Iyengar K, Jain M, Thomas S, Dashora K, Liu W, Saini P, et al. Adherence to evidence based care practices for childbirth before and after a quality improvement intervention in health facilities of Rajasthan, India. BMC Pregnancy Childbirth. 2014;14(1):1-12.

40. Sk MIK, Paswan, B., Anand, A. et al. Praying until death: revisiting three delays model to contextualise the socio-cultural factors associated with maternal deaths in a region with high prevalence of eclampsia in India. BMC Pregnancy Childbirth 19, $314(2019)$. https://doi.org/10.1186/s12884-019-2458-5

41. Iliyasu Z, Abubakar IS, Galadanci HS, Aliyu MH. Birth preparedness, complication readiness and fathers' participation in maternity care in a northern Nigerian community. Afr J Reprod Health [Internet]. 2010;14(1):21-32. Available from:

http://www.ncbi.nlm.nih.gov/pubmed/20695136

42. International Institute for Population Sciences. State Fact Sheet - Uttar Pradesh. Natl Fam Heal Surv - 4 2015-16 [Internet]. $2016 ; 1-4$. Available from: http://rchiips.org/nfhs/pdf/NFHS4/UP_FactSheet.pdf

43. Office of Registrar General, India,. Annual Health Survey (AHS) in 8 EAG States and Assam - Release of AHS Bulletin: $2010-11$ [Internet]. 2011 [cited 2017 Nov 16]. Available from: http://censusindia.gov.in/vital_statistics/AHSBulletins/files/AHSpr.pdf

44. International Institute for Population Sciences. National Family Health Survey - 4 2015-2016 State Fact Sheet Uttar Pradesh. IIPS. Mumbai; 2015.

45. Yamey G. Scaling up global health interventions: A proposed framework for success. PLOS Medicine 8(6): e1001049. https://doi.org/10.1371/journal.pmed.1001049

46. Cislaghi B, Denny EK, Cissé M, Gueye P, Shrestha B, Shrestha PN, et al. Changing Social Norms: the Importance of "Organized Diffusion" for Scaling Up Community Health Promotion and Women Empowerment Interventions. Prev Sci. 2019;20(6):936-46. doi:10.1007/s11121-019-00998-3

47. Green LW, Ottoson JM, García C, Hiatt RA. Diffusion theory and knowledge dissemination, utilisation, and integration in public health. Annu Rev Public Health. 2009;30:151-174. doi:10.1146/annurev.publhealth.031308.100049

48. Viswanath K, Steele WR, Finnegan JR. Social capital and health: Civic engagement, community size, and recall of health massages. Am J Public Health. 2006;96(8):1456-61. 61. doi:10.2105/AJPH.2003.029793

49. Khan ME, Agrawal PK, Hazra A, Ahmad J, Ahmad D, Dixit A, et al. Maternal and newborn health behaviors in rural Uttar Pradesh: Findings from learning phase baseline survey 2013." New Delhi: Population Council. https://knowledgecommons.popcouncil.org/departments_sbsr-rh/957/ 
50. Vital Statistics Division. Annual Health Survey: 2012-13 Fact Sheet - Uttar Pradesh. 2013;1-223.

https://www.censusindia.gov.in/vital_statistics/ahsbulletins/ahs_factsheets_2012-13/factsheet-uttar_pradesh.pdf

51. Kawachi I, Kennedy BP, Glass R. Social capital and self-rated health: A contextual analysis. Am J Public Health. 1999;89(8):1187-93.

52. Ogden J, Morrison K, Hardee K. Social capital to strengthen health policy and health systems. Health Policy Plan. 2014;29(8):1075-85.

53. Manandhar et al. Articles Effect of a participatory intervention with women's groups on birth outcomes in Nepal: cluster-randomised controlled trial. www.thelancet.com [Internet]. 2004 [cited 2017 Dec 2];364(11). https://doi.org/10.1016/S0140-6736(04)17021-9

54. Kumar V, Kumar A, Ghosh AK, Samphel R, Yadav R, Yeung D, et al. Enculturating science: Community-centric design of behavior change interactions for accelerating health impact. Semin Perinatol [Internet]. 2015;39(5):393-415. Available from: http://dx.doi.org/10.1053/j.semperi.2015.06.010

55. Baqui AH, Williams EK, Rosecrans AM, Agrawal PK, Ahmed S, Darmstadt GL, et al. Impact of an integrated nutrition and health programme on neonatal mortality in rural northern India. Bull World Health Organ. 2008;86(10):796-804.

56. Kumar V, Mohanty S, Kumar A, Misra RP, Santosham M, Awasthi S, et al. Effect of community-based behaviour change management on neonatal mortality in Shivgarh, Uttar Pradesh, India: a cluster-randomised controlled trial. Lancet. 2008;372(9644):1151-62.

57. Prost A, Colbourn T, Seward N, Azad K, Coomarasamy A, Copas A, et al. Women's groups practising participatory learning and action to improve maternal and newborn health in low-resource settings: A systematic review and meta-analysis. Lancet [Internet]. 2013;381(9879):1736-46. Available from: http://dx.doi.org/10.1016/S0140-6736(13)60685-6

58. Gage AJ. Barriers to the utilisation of maternal health care in rural Mali. Soc Sci Med. 2007;65(8):1666-82. https://doi.org/10.1016/j.socscimed.2007.06.001

59. Hazra A, Atmavilas Y, Hay K, Saggurti N, Verma RK, Ahmad J, et al. Effects of health behaviour change intervention through women's selfhelp groups on maternal and newborn health practices and related inequalities in rural india: A quasi-experimental study.

EClinicalMedicine [Internet]. 2020;18:100198. Available from: https://doi.org/10.1016/j.eclinm.2019.10.011

60. Walia M, Irani L, Chaudhuri I, Atmavilas Y, Saggurti N. Effect of sharing health messages on antenatal care behavior among women involved in microfinance-based self-help groups in Bihar India. Glob Heal Res Policy. 2020;5(1):1-8.

61. Steckler A, Goodman RM, Mcleroy KR, Goodman RM, Ph D, Davis S. Measuring the Diffusion of Innovative Health Promotion Programs. 1992;214-24.

62. Dearing JW. Evolution of Diffusion and Dissemination Theory. 2008;14(2):99-108.

63. Saggurti N, Atmavilas Y, Porwal A, Schooley J, Das R, Kande N, et al. Effect of health intervention integration within women's self-help groups on collectivisation and healthy practices around reproductive, maternal, neonatal and child health in rural India. PLoS One [Internet]. 2018;13(8):1-15. Available from: http://dx.doi.org/10.1371/journal.pone.0202562

64. Singh R, Neogi SB, Hazra A, Irani L, Ruducha J, Ahmad D, Kumar S, Mann N, Mavalankar D. Utilization of maternal health services and its determinants: a cross-sectional study among women in rural Uttar Pradesh, India. J Heal Popul Nutr [Internet]. 2019;38(13):1-12. Available from: http://doi.org/10.1186/s41043-019-0173-5

65. Lyngdoh T, Neogi SB, Ahmad D, Soundararajan S, Mavalankar D. Intensity of contact with frontline workers and its influence on maternal and newborn health behaviors: cross-sectional survey in rural Uttar Pradesh, India. J Health Popul Nutr. 2018;37(1):2. Published 2018 Jan 8. doi:10.1186/s41043-017-0129-6

66. Ruducha J, Hariharan D, Potter J, et alMeasuring coordination between women's self-help groups and local health systems in rural India: a social network analysisBMJ Open 2019;9:e028943. doi: 10.1136/bmjopen-2019-028943

67. Census of India: Provisional Population Totals Paper 1 of 2011 : Uttar Pradesh [Internet]. [cited 2019 Nov 30]. Available from: http://www.censusindia.gov.in/2011-prov-results/prov_data_products_up.html

68. Ruducha J, Huang X, Potter J, Hariharan D, Ahmad D, Kumar S, et al. Perceived Social Networks and Newborn Health: Evidence from SelfHelp Group Communities in Northern India. Societies [Internet]. 2018;8(4):92. Available from: http://doi.org/10.3390/soc8040092

69. Devasenapathy N, Neogi SB, Soundararajan S, Ahmad D, Hazra A, Ahmad J, et al. Association of antenatal care and place of delivery with newborn care practices: evidence from a cross-sectional survey in rural Uttar Pradesh, India. J Heal Popul Nutr [Internet]. 2017;36(1):30. Available from: http://doi.org/10.1186/s41043-017-0107-z

70. Issac A, Chatterjee S, Srivastava A, Bhattacharyya S. Out of pocket expenditure to deliver at public health facilities in India: A cross sectional analysis. Reprod Health [Internet]. 2016;13(1):1-9. Available from: http://dx.doi.org/10.1186/s12978-016-0221-1

71. Soubeiga, Dieudonné, Gauvin, Lise, Hatem MA, Johri M. Birth Preparedness and Complication Readiness (BPCR) interventions to reduce maternal and neonatal mortality in developing countries: systematic review and meta-analysis. BMC Pregnancy Childbirth [Internet]. 2014;14(129):1-11. Available from: https://bmcpregnancychildbirth.biomedcentral.com/articles/10.1186/1471-2393-14-129 


\section{Tables}

Table 1

Levels of birth preparedness and complication readiness practice in last pregnancy among women aged $15-49$ in rural Uttar Pradesh $(n=$ $17,244)$

\begin{tabular}{|c|c|c|}
\hline Level of Preparedness & $\begin{array}{l}\text { Number } \\
(\%)\end{array}$ & Specific Activity Done \\
\hline No BPCR Preparedness & $4,187(24)$ & \\
\hline \multirow[t]{5}{*}{ Only Birth preparedness done } & \multirow[t]{5}{*}{$955(6)$} & 0. Decided on the place of delivery (at home or health facility) \\
\hline & & 1. Knew the facility that could provide emergency care \\
\hline & & 3. Identified people to accompany the woman \\
\hline & & 5. Identified people to take care of children at home \\
\hline & & 7. Others(oil/cloth/soap) \\
\hline \multirow[t]{3}{*}{ Only Complication Readiness done } & \multirow[t]{3}{*}{$3,697(21)$} & $\begin{array}{l}\text { 1. Saved/arranged money for delivery expense or in case of } \\
\text { emergency }\end{array}$ \\
\hline & & 3. Advance arrangement of transportation to go to the facility \\
\hline & & 5. Identified institution where to rush in case of emergency \\
\hline \multirow{8}{*}{$\begin{array}{l}\text { Both Birth Preparation and Complication Readiness } \\
\text { Steps done }\end{array}$} & \multirow[t]{8}{*}{$8,405(49)$} & 1. Decided on the place of delivery-home or health facility \\
\hline & & 3. Knew the facility that could provide emergency care \\
\hline & & 5. Identified people to accompany the woman \\
\hline & & 7. Identified people to take care of children at home \\
\hline & & $\begin{array}{l}\text { 9. Saved/arranged money for delivery expense or in case of } \\
\text { emergency }\end{array}$ \\
\hline & & 11. Advance arrangement of transportation to go to the facility \\
\hline & & 13. Identified institution where to rush in case of emergency \\
\hline & & 15. Others(oil/cloth/soap) \\
\hline Total & $\begin{array}{l}17,244 \\
(100)\end{array}$ & \\
\hline
\end{tabular}


Summary statistics of variables by the Non-Self Help Group [Non-member] Household and Self-Help Group [SHG] Households with $n=17,244$ eligible women.

\begin{tabular}{|c|c|c|c|}
\hline \multirow[b]{2}{*}{ Sr.no } & \multirow[b]{2}{*}{ Variable } & \multicolumn{2}{|c|}{ Summary Statistics(N = 17,244) } \\
\hline & & $\begin{array}{l}\text { Non- member } \\
\text { Households }\end{array}$ & SHG Households \\
\hline & Independent Variables: Program Exposure Characteristics & & \\
\hline \multirow[t]{2}{*}{1.} & \multirow[t]{2}{*}{ Level of Household (HH) Microfinance (MF) Exposure } & 10,097 & 7,147 \\
\hline & & $(59 \%)$ & $(41 \%)$ \\
\hline & \multirow[t]{2}{*}{ 4. $\mathrm{HH}$ in a village with no SHG, no health intervention (Pure control-reference) } & 3709 & - \\
\hline & & $(37 \%)$ & \\
\hline & \multirow[t]{2}{*}{ 1. Non-Member Household in a village with SHG only program } & 3042 & - \\
\hline & & $(30 \%)$ & \\
\hline & \multirow[t]{2}{*}{ 2. Non-Member Household in a village with SHG plus health intervention } & 3346 & - \\
\hline & & $(33 \%)$ & \\
\hline & \multirow[t]{2}{*}{ 3. (SHG) Member Household in a village with SHG only intervention } & \multirow[t]{2}{*}{-} & 3623 \\
\hline & & & $(51 \%)$ \\
\hline & \multirow[t]{2}{*}{ 4. (SHG plus Health) Member Household in a village with SHG plus Health intervention } & - & 3524 \\
\hline & & & $(49 \%)$ \\
\hline \multirow[t]{6}{*}{2.} & \multicolumn{3}{|l|}{ Evaluation Survey Round } \\
\hline & \multirow[t]{2}{*}{ Round 1/ Baseline-2015 (=0) } & 5,454 & 3,269 \\
\hline & & $(54 \%)$ & $(45 \%)$ \\
\hline & \multirow[t]{2}{*}{ Round 2/ Endline-2017 (= 1) } & 4,643 & 3,878 \\
\hline & & $(45 \%)$ & $(54 \%)$ \\
\hline & \multicolumn{3}{|l|}{ Independent Variables: Individual Health and Health System Characteristics } \\
\hline \multirow[t]{2}{*}{3.} & \multirow[t]{2}{*}{ Parity (number of previous pregnancies) of Eligible Woman } & Mean $=2 \cdot 4$ & Mean $=2 \cdot 4$ \\
\hline & & $(S D=1 \cdot 44)$ & $(S D=1 \cdot 41)$ \\
\hline \multirow[t]{4}{*}{4.} & \multicolumn{3}{|l|}{ Any Past Pregnancy Loss (due to spontaneous/induced abortion) } \\
\hline & \multirow[t]{2}{*}{ No Previous Pregnancy loss (reference) } & 7,547 & 5,257 \\
\hline & & $(75 \%)$ & $(74 \%)$ \\
\hline & Previous Pregnancy loss & $2,550(25 \%)$ & $1,890(26 \%)$ \\
\hline \multirow[t]{5}{*}{5.} & \multicolumn{3}{|l|}{ Any Complication experienced in last pregnancy/labour or post-partum } \\
\hline & \multirow[t]{2}{*}{ No Complication Experienced (reference) } & 5,313 & 3,710 \\
\hline & & $(53 \%)$ & $(52 \%)$ \\
\hline & \multirow[t]{2}{*}{ Complication experienced } & 4,784 & 3,437 \\
\hline & & $(47 \%)$ & $(48 \%)$ \\
\hline \multirow[t]{3}{*}{6.} & \multicolumn{3}{|l|}{$\begin{array}{l}\text { Eligible woman's knowledge of the minimum number of Antenatal Check-up (ANC) } \\
\text { required during pregnancy }\end{array}$} \\
\hline & \multirow[t]{2}{*}{ Incorrect knowledge (reference) } & 6,381 & 4,386 \\
\hline & & $(63 \%)$ & $(61 \%)$ \\
\hline
\end{tabular}


Correct knowledge

$\begin{array}{ll}3,716 & 2,761 \\ (37 \%) & (39 \%)\end{array}$

7. Received Four or more ANC in last pregnancy (with urine/blood pressure /weight/abdominal/ultrasound tested in last ANC)

Not received (reference)

$7,429 \quad 5,070$

Received four ANC with all tests done in last ANC

2,668

2,077

(26\%)

8. Place of Last Delivery

Home Delivery (reference)

1,740

1,199

(17\%)

Institutional Delivery

8,357

5948

(83\%)

9. Duration (in hours) of stay in Health Facility immediately after delivery

1. Home Delivery (reference)

$1,740(17 \%)$

$1,199(17 \%)$

2. Discharged within $12 \mathrm{hrs}$

$5,603(56 \%)$

$4,127(58 \%)$

3. Discharged between 12-24 hrs

$1,134(11 \%)$

$795(11 \%)$

4. Discharged between $24-48$ hrs

$720(7 \%)$

$506(7 \%)$

5. Discharged between $48-72$ hrs

$283(3 \%)$

$146(2 \%)$

6. Discharged after $>72 \mathrm{hrs}$

$617(6 \%)$

$374(5 \%)$

10. Received Three PNC in First Seven Days after Delivery

Not Received

Received 3 PNC in first Seven Days after Delivery

11. Number of contact with ASHA/ANM/AWW/SHG in last pregnancy

$\begin{array}{ll}9,188(91 \%) & 6,488(91 \%) \\ 909(9 \%) & 659(9 \%) \\ \text { Mean }=4 \cdot 0 & \text { Mean }=4 \cdot 23 \\ (S D=5 \cdot 4) & (S D=5 \cdot 4)\end{array}$

12. Distance (Kilometre) to Primary health Centre if not available in the village

Mean $=5 \cdot 4$

Mean $=5 \cdot 4$

$(\mathrm{SD}=4.9)$

$(S D=4 \cdot 7)$

Independent Variables: Sociodemographic/Economic, and Area Level Characteristics

13. Village distance (Kilometre) to closest town

Mean $=1 \cdot 47$

Mean $=1 \cdot 49$

14. Population of Village

$(\mathrm{SD}=0.77) \quad(\mathrm{SD}=0.75)$

Mean $=5,153$

Mean $=5,140$

$(\mathrm{SD}=5,134)$

$(S D=5,113)$

15. Household (HH) with Below Poverty Line (BPL) Card

$\mathrm{HH}$ without BPL Card -reference

$5,598(55 \%)$

$3,831(54 \%)$

$\mathrm{HH}$ with BPL Card

$4,499(45 \%)$

$3316(46 \%)$

16. Household Wealth Quintile (Poor to Poorest)
1. Marginally Poor
1,985 (20\%)
1,498 (21\%)
2. Moderately Poor
$2,049(20 \%)$
1,502 (21\%) 


\begin{tabular}{|c|c|c|c|}
\hline & & Summary St & $(N=17,244)$ \\
\hline & 3. Poor & $1,994(20 \%)$ & $1,471(20 \%)$ \\
\hline & 4. Poorer & $2,029(20 \%)$ & $1,396(20 \%)$ \\
\hline & 5. Poorest & $2,040(20 \%)$ & $1,280(18 \%)$ \\
\hline 17. & Eligible Woman Presently Working to earn in cash, kind or both & & \\
\hline & Not Working & $8,436(84 \%)$ & $5,936(83 \%)$ \\
\hline & presently working & $1,661(16 \%)$ & $1,211(17 \%)$ \\
\hline 18. & Family Type & & \\
\hline & Nuclear (reference) & 4,278 & 2,888 \\
\hline & & $(42 \%)$ & $(40 \%)$ \\
\hline & Joint and Extended Family & 5,819 & 4,259 \\
\hline & & $(58 \%)$ & $(60 \%)$ \\
\hline 19. & Religion & & \\
\hline & Muslim (reference) & 816 & 601 \\
\hline & & $(8 \%)$ & $(8 \%)$ \\
\hline & Hinduism and Others & 9,281 & 6,546 \\
\hline & & $(92 \%)$ & $(92 \%)$ \\
\hline 20. & Scheduled Caste & & \\
\hline & General Caste & 1,250 & 873 \\
\hline & & $(12 \%)$ & $(12 \%)$ \\
\hline & Other Backward Caste & 4,362 & 3,072 \\
\hline & & $(43 \%)$ & $(43 \%)$ \\
\hline & Scheduled Caste and Scheduled Tribe & 4,485 & 3,202 \\
\hline & & $(45 \%)$ & $(45 \%)$ \\
\hline 21. & Eligible Woman (EW) Age in completed years & Mean $=25$ & Mean $=25$ \\
\hline & & $(\mathrm{SD}=4 \cdot 56)$ & $(\mathrm{SD}=4 \cdot 55)$ \\
\hline 22. & Eligible Woman's (EW's) Education Level & & \\
\hline & No schooling (reference) & 3,417 & 2,349 \\
\hline & & $(34 \%)$ & $(33 \%)$ \\
\hline & Completed Primary/Middle School (up to year nine) and above & 6,680 & 4,798 \\
\hline & & $(66 \%)$ & $(67 \%)$ \\
\hline 23. & EW's Husband Education Level & & \\
\hline & No schooling(reference) & 1,732 & 1,211 \\
\hline & & $(17 \%)$ & $(17 \%)$ \\
\hline & Completed Primary/Middle School (up to year nine) and above & 8,365 & 5,936 \\
\hline & & $(83 \%)$ & $(83 \%)$ \\
\hline & Dependent Variable & & \\
\hline 24. & Eligible woman's level of Birth Preparedness and Complication Readiness (BPCR) & 10,097 & 7,147 \\
\hline & & $(59 \%)$ & $(41 \%)$ \\
\hline
\end{tabular}




\begin{tabular}{|lll|}
\hline & \multicolumn{2}{c|}{ Summary Statistics $(\mathrm{N}=17,244)$} \\
\hline Incomplete or no BPCR steps (reference) & 5,435 & 3,404 \\
& $(53 \%)$ & $(48 \%)$ \\
\hline Complete BPCR steps practiced in last Pregnancy & 4,662 & 3,743 \\
\hline
\end{tabular}

Table 3

Results of the logistic regression models I and II Estimating the levels of Birth and Complication Readiness Practice; Odds Ratio (OR) and associated $95 \%$ confidence intervals are reported: OR $(95 \% \mathrm{Cl})$.

\begin{tabular}{|c|c|c|c|}
\hline \multirow[b]{2}{*}{ S.no } & \multirow[b]{2}{*}{ Explanatory Variable name } & \multicolumn{2}{|l|}{ Main Effects } \\
\hline & & Model I & Model II \\
\hline & & Odds Ratio & Odds Ratio \\
\hline & & $95 \% \mathrm{Cl}$ & $95 \% \mathrm{Cl}$ \\
\hline & Main Effects & & \\
\hline \multirow[t]{4}{*}{1.} & \multicolumn{3}{|l|}{ Level of Household (HH) Microfinance (MF) Exposure } \\
\hline & 1. $\mathrm{HH}$ in a village with no program intervention (Pure control-reference) & - & - \\
\hline & \multirow[t]{2}{*}{ 2. Non-Member Household in village with SHG or SHG + health program } & $0.89 * \star \star$ & $0.69 * \star \star$ \\
\hline & & $(0.82-0.97)$ & $(0.61-0.77)$ \\
\hline & \multirow[t]{2}{*}{ 3. SHG: Member Household in village with SHG only intervention } & $1 \cdot 17^{\star \star \star}$ & $1 \cdot 13^{*}$ \\
\hline & & $(1 \cdot 07-1 \cdot 29)$ & $(0 \cdot 98-1 \cdot 30)$ \\
\hline & \multirow[t]{2}{*}{ 4. SHG + Health: Member Household in village with SHG plus Health intervention } & $1 \cdot 48^{\star \star \star}$ & 0.96 \\
\hline & & $(1 \cdot 35-1 \cdot 63)$ & $(0 \cdot 84-1 \cdot 11)$ \\
\hline \multirow[t]{4}{*}{2.} & \multicolumn{3}{|l|}{ Round } \\
\hline & \multicolumn{3}{|l|}{ Round 1 (reference) } \\
\hline & \multirow[t]{2}{*}{ Round 2} & $0 \cdot 37 \star \star \star$ & $0 \cdot 25^{\star \star \star}$ \\
\hline & & $(0.35-0.39)$ & $(0.22-0.29)$ \\
\hline \multirow[t]{4}{*}{3.} & \multicolumn{3}{|l|}{ Two-way Interaction Effects: Round \# Households (HH) Microfinance (MF) Exposure } \\
\hline & \multicolumn{3}{|l|}{ Round 1\# Non-MF HH in Pure Control village (reference) } \\
\hline & \multirow[t]{2}{*}{ Round 2 \# Non-MF HH in a village with MF or MF plus Health } & \multirow[t]{2}{*}{-} & $1 \cdot 73^{\star \star \star}$ \\
\hline & & & $(1 \cdot 46-2 \cdot 05)$ \\
\hline & \multirow[t]{2}{*}{ Round2 \# SHG Member HH in village with MF program only } & \multirow[t]{2}{*}{-} & $1 \cdot 10$ \\
\hline & & & $(0.90-1.33)$ \\
\hline & \multirow[t]{2}{*}{ Round2 \# SHG + Health Member HH in village with MF plus health intervention } & \multirow[t]{2}{*}{-} & $2 \cdot 21^{\star \star \star}$ \\
\hline & & & $(1.82-2 \cdot 68)$ \\
\hline
\end{tabular}


Results of the logistic regression models III and IV Estimating the levels of Birth and Complication Readiness Practice using Confounders; Odds Ratio (OR) and associated $95 \%$ confidence intervals are reported: OR $(95 \% \mathrm{Cl})$.

\begin{tabular}{|c|c|c|c|}
\hline \multirow[b]{2}{*}{ S.no } & \multirow[b]{2}{*}{ Explanatory Variable name } & \multicolumn{2}{|c|}{$\begin{array}{l}\text { Secondary Effects } \\
\text { Using confounders }\end{array}$} \\
\hline & & Model III & $\begin{array}{l}\text { Model } \\
\text { IV }\end{array}$ \\
\hline & & & $\begin{array}{l}\text { Odds } \\
\text { Ratio }\end{array}$ \\
\hline & & $95 \% \mathrm{Cl}$ & $95 \% \mathrm{Cl}$ \\
\hline \multirow[t]{8}{*}{1.} & Level of Household (HH) Microfinance (MF) Exposure & & \\
\hline & 1. $\mathrm{HH}$ in a village with no program intervention (Pure control-reference) & & \\
\hline & 2. Non-Member Household in a village with SHG or SHG + health program & $0 \cdot 69 * \star \star$ & $0 \cdot 70 * \star \star$ \\
\hline & & $(0.61-0.78)$ & $\begin{array}{l}(0.62- \\
0.78)\end{array}$ \\
\hline & 3. (SHG) Member Household in a village with SHG only intervention & $1 \cdot 13^{\star}$ & $1 \cdot 14^{\star}$ \\
\hline & & $(0 \cdot 98-1 \cdot 30)$ & $\begin{array}{l}(0.99- \\
1 \cdot 31)\end{array}$ \\
\hline & 4. (SHG + health) Member Household in a village with SHG plus Health intervention & 0.97 & 0.98 \\
\hline & & $(0 \cdot 84-1 \cdot 11)$ & $\begin{array}{l}(0.85- \\
1 \cdot 12)\end{array}$ \\
\hline \multirow[t]{4}{*}{2} & Round & & \\
\hline & Round 1 (reference) & & \\
\hline & Round 2 & 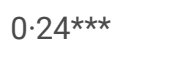 & $0 \cdot 24 * \star \star$ \\
\hline & & $(0 \cdot 21-0 \cdot 28)$ & $\begin{array}{l}(0.20- \\
0 \cdot 27)\end{array}$ \\
\hline \multirow[t]{8}{*}{3.} & Two-way Interaction Effects (Round \# SHG Exposure) & & \\
\hline & Round 1\# Non-MF HH in Pure Control village (reference) & & \\
\hline & Round 2 \# Non-MF HH in village with MF or MF plus Health & $1 \cdot 72^{\star \star \star}$ & $1 \cdot 72^{\star \star \star}$ \\
\hline & & $(1 \cdot 45-2 \cdot 04)$ & $\begin{array}{l}(1 \cdot 45- \\
2 \cdot 04)\end{array}$ \\
\hline & Round2 \# MF-HH in village with MF only & $1 \cdot 10$ & $1 \cdot 10$ \\
\hline & & $(0 \cdot 90-1 \cdot 33)$ & $\begin{array}{l}(0.90- \\
1 \cdot 33)\end{array}$ \\
\hline & Round2 \# MF + Health HH in village with MF plus health & $2 \cdot 20 * \star \star$ & $2 \cdot 20 * \star \star$ \\
\hline & & $(1 \cdot 82-2 \cdot 67)$ & $\begin{array}{l}(1 \cdot 81- \\
2 \cdot 66)\end{array}$ \\
\hline \multicolumn{4}{|c|}{ Model III-Individual Health and Health System variables } \\
\hline 4. & Parity (number of previous pregnancies) of Eligible Woman & 0.98 & 0.98 \\
\hline & & $(0 \cdot 96-1 \cdot 00)$ & $\begin{array}{l}(0.95- \\
1.01)\end{array}$ \\
\hline 5. & Any Past Pregnancy Loss (due to spontaneous/induced abortion) & & \\
\hline & No Previous Pregnancy loss (reference) & & \\
\hline
\end{tabular}


Secondary Effects

Using confounders

Previous Pregnancy loss

$\begin{array}{ll}0.98 & 0.98 \\ (0.91-1.05) & (0.90- \\ 1.05)\end{array}$

6. Any Complication experienced in last pregnancy/labour or postpartum

No Complication Experienced (reference)

Complication experienced

$\begin{array}{ll}0.95 & 0.95 \\ (0.89-1.01) & (0.89- \\ 1.01)\end{array}$

7. Eligible woman's knowledge of the minimum number of ANC required during pregnancy

incorrect knowledge (reference)

correct knowledge

$\begin{array}{ll}1.07 * \star & 1.06 * \\ (1.00-1 \cdot 14) & (0.99- \\ & 1 \cdot 13)\end{array}$

8. Received four or more Antenatal Check-up (ANC) in last pregnancy with urine/blood pressure /weight/abdominal/ultrasound test in last ANC

Not received (reference)

Received 4 ANC with all tests done in last ANC

$\begin{array}{ll}0.92 & 0.91 \text { *夫 } \\ (0.85-1.01) & (0.82- \\ 0.99)\end{array}$

\section{Place of Last Delivery}

Home Delivery (reference)

Institutional Delivery

$\begin{array}{ll}0.95 & 0.92 \\ (0.81-1.11) & (0.79- \\ 1.08)\end{array}$

10. Duration (in hours) of stay in Health Facility immediately after delivery

Home Delivery (reference)

Discharged within 12 hrs

$1 \cdot 14^{\star} \quad 1 \cdot 15^{\star \star}$

$(0.98-1.31) \quad(0.99-$

$1 \cdot 33)$

Discharged between 12-24 hrs

$1.09 \quad 1.10$

$(0.92-1.29) \quad(0.93-$

$1 \cdot 30)$

Discharged between 24-48 hrs

$0.98 \quad 0.99$

$(0 \cdot 82-1 \cdot 17)$

Discharged between 48-72 hrs

$1 \cdot 02$

$1 \cdot 05$

$(0 \cdot 81-1 \cdot 29)$

Discharged after $>72 \mathrm{hrs}$

$1 \cdot 00$

$1 \cdot 00$

11. Received 3 PNC in first Seven Days after Delivery

Not Received any PNC or Received after 7 days

Note: Confidence intervals in parentheses; and significant $p$-value showing ***: $p<0.01, * *$ : $p<0.05$ and *: $p<0 \cdot 10$ levels. Log-likelihood and $\mathrm{AIC/BIC}$ values were also reported. 


\begin{tabular}{|c|c|c|c|}
\hline & & $\begin{array}{l}\text { Secondary Ef } \\
\text { Using confou }\end{array}$ & ts \\
\hline & Received 3 PNC in first Seven Days after Delivery & 1.06 & $1 \cdot 05$ \\
\hline & & $(0.95-1 \cdot 19)$ & $\begin{array}{l}(0.94- \\
1 \cdot 18)\end{array}$ \\
\hline 12. & Number of contact with ASHA/ANM/AWW/SHG in last pregnancy & 0.99 & $1 \cdot 00$ \\
\hline & & $(0.99-1 \cdot 00)$ & $\begin{array}{l}(0.99- \\
1.00)\end{array}$ \\
\hline 13. & Distance to Primary health Centre if not available in the village & 0.99 & 0.99 \\
\hline & & $(0.98-1 \cdot 00)$ & $\begin{array}{l}(0.99- \\
1.00)\end{array}$ \\
\hline & Socio-Demographic/Economic and Area Level Variables & & \\
\hline 14. & Distance to closest town & - & 0.99 \\
\hline & & & $\begin{array}{l}(1 \cdot 03- \\
1 \cdot 13)\end{array}$ \\
\hline 15. & Population of Village & - & $1 \cdot 00$ \\
\hline & & & $\begin{array}{l}(0.99- \\
1.00)\end{array}$ \\
\hline 16. & Household (HH) with Below Poverty Line (BPL) Card & & \\
\hline & No BPL Card (reference) & & \\
\hline & Yes-HH has BPL Card & - & $1 \cdot 01$ \\
\hline & & & $\begin{array}{l}(0.94- \\
1.08)\end{array}$ \\
\hline 17. & Household Wealth Quintile (Poor to Poorest) & & \\
\hline & 1. Marginally Poor (reference) & & \\
\hline & 2. Moderately Poor & - & $1 \cdot 11^{\star *}$ \\
\hline & & & $\begin{array}{l}(1 \cdot 00- \\
1 \cdot 22)\end{array}$ \\
\hline & 3. Poor & - & $1 \cdot 00$ \\
\hline & & & $\begin{array}{l}(0 \cdot 90- \\
1 \cdot 10)\end{array}$ \\
\hline & 4. Poorer & - & $0.91 *$ \\
\hline & & & $\begin{array}{l}(0 \cdot 81- \\
1 \cdot 01)\end{array}$ \\
\hline & 5. Poorest & - & $0.87 * \star$ \\
\hline & & & $\begin{array}{l}(0.77- \\
0.97)\end{array}$ \\
\hline 18. & Eligible Woman Presently Working to eam in cash, in kind or both & & \\
\hline & Not working (reference) & & \\
\hline & Currently working & - & $1 \cdot 00$ \\
\hline & & & $\begin{array}{l}(0.92- \\
1.09)\end{array}$ \\
\hline 19. & Family Type & & \\
\hline
\end{tabular}

Note: Confidence intervals in parentheses; and significant $p$-value showing ***: $p<0.01, * *: p<0.05$ and *: $p<0 \cdot 10$ levels. Log-likelihood and AIC/BIC values were also reported. 


\begin{tabular}{|c|c|c|c|}
\hline & & \multicolumn{2}{|c|}{$\begin{array}{l}\text { Secondary Effects } \\
\text { Using confounders }\end{array}$} \\
\hline & \multicolumn{3}{|l|}{ Nuclear (reference) } \\
\hline & \multirow[t]{2}{*}{ Joint \& Extended Family } & - & $1 \cdot 05$ \\
\hline & & & $\begin{array}{l}(0 \cdot 98- \\
1 \cdot 13)\end{array}$ \\
\hline \multirow[t]{4}{*}{20.} & \multicolumn{3}{|l|}{ Religion } \\
\hline & \multicolumn{3}{|l|}{ Muslim (reference) } \\
\hline & \multirow[t]{2}{*}{ Hinduism \& Others } & \multirow[t]{2}{*}{-} & $1 \cdot 06$ \\
\hline & & & $\begin{array}{l}(0 \cdot 94- \\
1 \cdot 19)\end{array}$ \\
\hline \multirow[t]{6}{*}{21.} & \multicolumn{3}{|l|}{ Scheduled Caste } \\
\hline & \multicolumn{3}{|l|}{ General Caste (reference) } \\
\hline & \multirow[t]{2}{*}{ Other Backward Caste } & \multirow[t]{2}{*}{-} & 0.96 \\
\hline & & & $\begin{array}{l}(0 \cdot 87- \\
1 \cdot 07)\end{array}$ \\
\hline & \multirow[t]{2}{*}{ Scheduled Caste \& Tribe } & \multirow[t]{2}{*}{-} & 0.97 \\
\hline & & & $\begin{array}{l}(0 \cdot 87- \\
1 \cdot 08)\end{array}$ \\
\hline \multirow[t]{2}{*}{22.} & \multirow[t]{2}{*}{ Eligible Woman (EW) Age in completed years } & \multirow[t]{2}{*}{-} & $1 \cdot 00$ \\
\hline & & & $\begin{array}{l}(0 \cdot 99- \\
1 \cdot 01)\end{array}$ \\
\hline \multirow[t]{4}{*}{23.} & \multicolumn{3}{|l|}{ Eligible Woman (EW) Education Level-Completed } \\
\hline & \multicolumn{3}{|l|}{ No schooling (reference) } \\
\hline & \multirow[t]{2}{*}{ Completed Primary School (year 9)\& Above } & \multirow[t]{2}{*}{-} & 0.96 \\
\hline & & & $\begin{array}{l}(0 \cdot 89- \\
1 \cdot 03)\end{array}$ \\
\hline \multirow[t]{2}{*}{24.} & \multicolumn{3}{|l|}{ EW's Husband Education Level } \\
\hline & \multicolumn{3}{|l|}{ No schooling (reference) } \\
\hline & \multirow[t]{2}{*}{ Completed Primary School (year 9) \& Above } & \multirow[t]{2}{*}{-} & $1 \cdot 06$ \\
\hline & & & $\begin{array}{l}(0 \cdot 97- \\
1 \cdot 17)\end{array}$ \\
\hline & Estimation of Model Fit & Model III & $\begin{array}{l}\text { Model } \\
\text { IV }\end{array}$ \\
\hline & Log likelihood & $-11,354$ & $-11,334$ \\
\hline & Number of Observation & 17,244 & 17,244 \\
\hline & $\mathrm{AIC} / \mathrm{BIC}$ & $22,750 / 22,914$ & $\begin{array}{l}22,741 / \\
23,021\end{array}$ \\
\hline Not & $\begin{array}{l}\text { nfidence intervals in parentheses; and significant } \\
\text { BIC values were also reported. }\end{array}$ & 10 levels. Log-lik & ihood \\
\hline
\end{tabular}

\section{Figures}




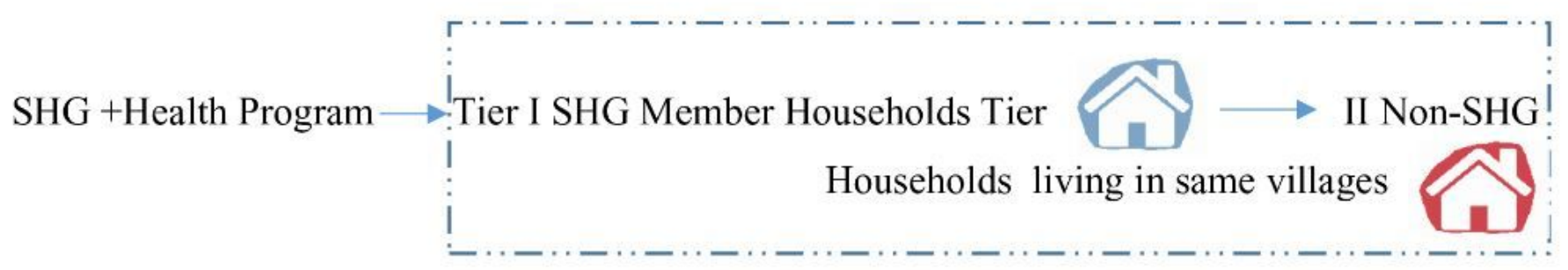

Figure 1

Assumed pathway of knowledge diffusion from member households (tier I) to neighbouring non-member households (tier II) in the same villages

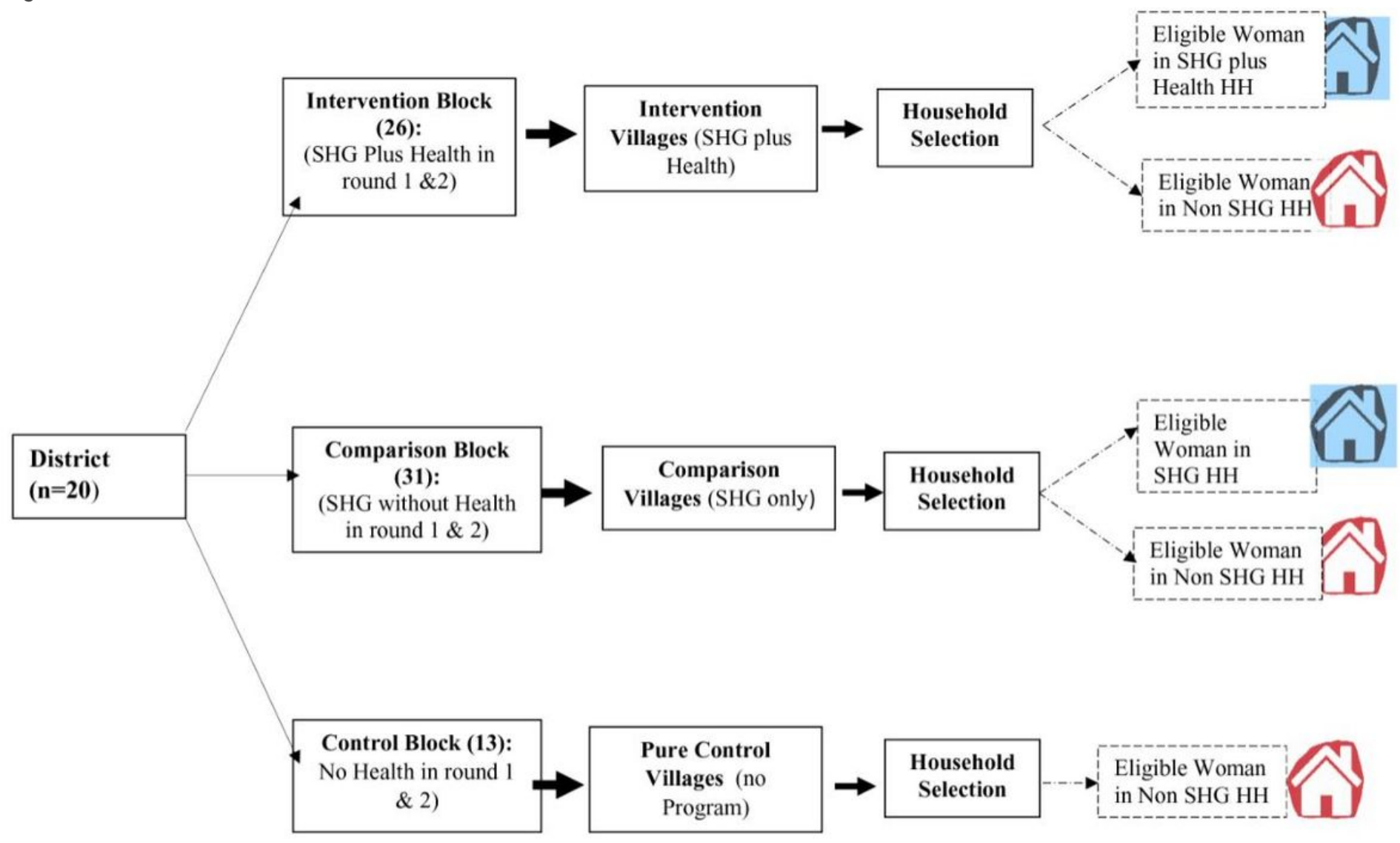

Figure 2

Three-stage survey sampling approach comprising block, village and household selection 
60

50

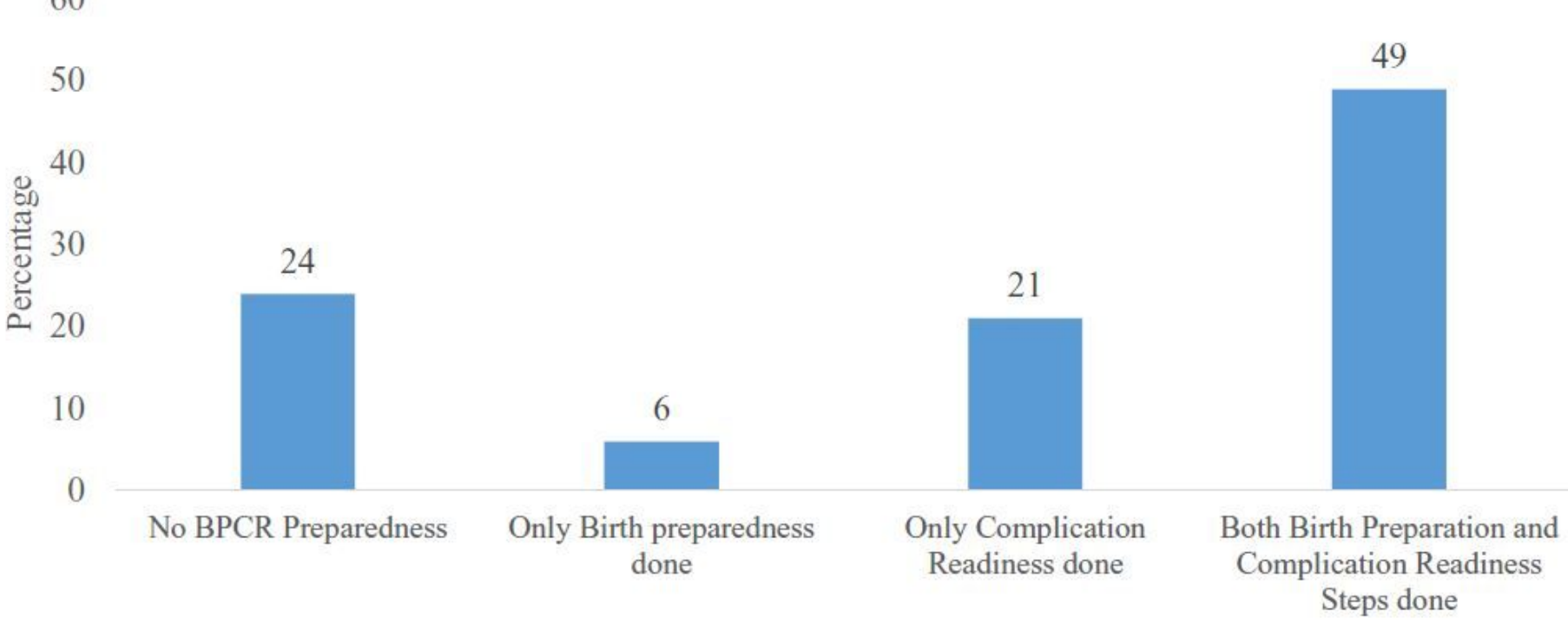

Figure 3

Percentage of women categorised accordingly to the level of birth preparedness and complication readiness 